\title{
Reconsidering hippocampal neurogenesis in Alzheimer's disease
}

\author{
Alonso Martinez-Canabal ${ }^{1,2 *}$ \\ ${ }^{1}$ Molecular Neuropathology Department, Cell Physiology Institute, National Autonomous University of Mexico, Mexico City, Mexico \\ ${ }^{2}$ Cell Biology Department, Faculty of Sciences, National Autonomous University of Mexico, Mexico City, Mexico \\ ${ }^{*}$ Correspondence: acanabal@ifc.unam.mx
}

Edited by:

João O. Malva, University of Coimbra, Portugal

Reviewed by:

José Luis Trejo, Institute Cajal - CSIC, Spain

Jorge Valero, University of Coimbra, Portugal

Keywords: Alzheimer disease, hippocampal neurogenesis, hAPP, dentate gyrus, progenitor cells

\section{A commentary on}

Wild-type neural progenitors divide and differentiate normally in an amyloid-rich environment

by Yetman, M. J., and Jankowsky, J. L. (2013). J. Neurosci. 33, 17335-17341. doi: 10.1523/JNEUROSCI.1917-13.2013

Hippocampal neurogenesis is often thought to be necessary to maintain hippocampus-dependent cognitive abilities (see references in Deng et al., 2010). Most investigations using transgenic animal models of Alzheimer's disease (AD) report a reduction in hippocampal neurogenesis (see references in $\mathrm{Mu}$ and Gage, 2011) giving rise to the idea that impaired neurogenesis has an important role during the onset and progression of the disease. In many animal models of $\mathrm{AD}$ with familial-type mutations, this decrease in neurogenesis is associated with the presence of toxic amyloid beta peptides $\left(A \beta_{42}\right)$ (Haughey et al., 2002). Nevertheless, some works with transgenic animals have shown that amyloid deposition increases neurogenesis (Jin et al., 2004a; Lopez-Toledano and Shelanski, 2007; Yu et al., 2009). There was also a work with no conclusive results in this regard (Ermini et al., 2008). Still, the most general view in the field is that $\mathrm{AD}$ related neuropathology damages hippocampal neurogenesis and in consequence impairs cognition. Therefore, it is surprising that in a recent study published in The Journal of Neuroscience, Yetman and Jankowsky (2013) show that strong overexpression of mutated human amyloid precursor protein (hAPP) has no impact on hippocampal neurogenesis when hAPP expression excludes the proliferative region of the dentate gyrus.

Despite a large amount of data generated from studies employing animal models of $\mathrm{AD}$, how hippocampal neurogenesis responds to $\mathrm{AD}$ in humans remains unclear. Some available data suggests that human $\mathrm{AD}$ is associated with a marked increase in the proliferation and survival of new neurons (Jin et al., 2004b; Perry et al., 2012). This works showed increased expression of neurogenesis markers not only during the onset but also during the middle and advanced stages of AD. Conversely Crews et al. (2010) reported a reduction in immature neurons during severe $\mathrm{AD}$, although this data is not as comprehensive as the work Perry et al. (2012). Nevertheless, some researchers suggest that this effect is merely an artifact of disease-induced changes to endothelial cells (Boekhoorn et al., 2006), or that this new neurons may substitute for neurons lost due to AD (Kuhn et al., 2007; Baron et al., 2008).

Yetman and Jankowsky (2013) aimed to determine whether neurogenesis deficits observed in animal models of $\mathrm{AD}$ are due to changes intrinsic to progenitor cells, changes extrinsic to progenitor cells, or both. So, they generated a transgenic mouse model of $\mathrm{AD}$ in which mature glutamatergic cells overexpress mutant hAPP, resulting in the deposition of amyloid plaques formation only in the granule cell layer. After 6 months of gene activation, amyloid plaques appeared throughout the forebrain. In the dentate gyrus, many amyloid plaques were observed in the molecular layer and hilus but not in the granule cell layer or the proliferative zone. Furthermore, there were no changes in the level of hippocampal neurogenesis (Figure 1). This finding of unchanged neurogenesis differs radically from findings of reduced neurogenesis in other transgenic models in which amyloid protein production is not restricted to specific cell types. Consequently, Yetman and Jankowsky (2013) suggest that the neurogenesis deficits observed in other transgenic models are due to toxicity resulting from hAPP directly produced by progenitor cells and immature cells. Therefore, conflicts found in transgenic animals literature could be clarified exploring the patters of expression of hAPP. Humans with $\mathrm{AD}$, however, do not exhibit reduced hippocampal neurogenesis (Perry et al., 2012). In addition, there is no evidence of APP expression in human neurogenic niche. Therefore, the transgenic mice used by Yetman and Jankowsky may be the currently existing animal model that most closely resembles human neuropathology.

The increase in hippocampal neurogenesis observed in humans with $\mathrm{AD}$ may possibly be due to disease-related inflammation. Variations in levels of inflammatory factors may affect neurogenesis by changing patterns of proliferation or survival of new cells. In particular, a strong inflammatory factor present in $\mathrm{AD}$, transforming growth factor beta 1 (TGF $\beta-1)$, increases the number of granule neurons (Martinez-Canabal et al., 2013b) and enhances neurogenesis (Battista et al., 2006). Two other molecular players may also contribute 
A Wild-type mouse

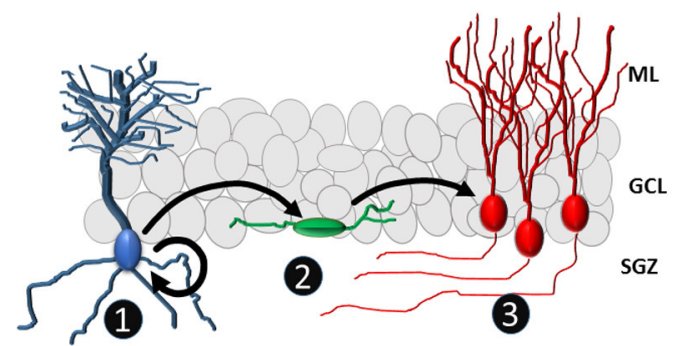

B hAPP-overexpressing mouse (most AD models)
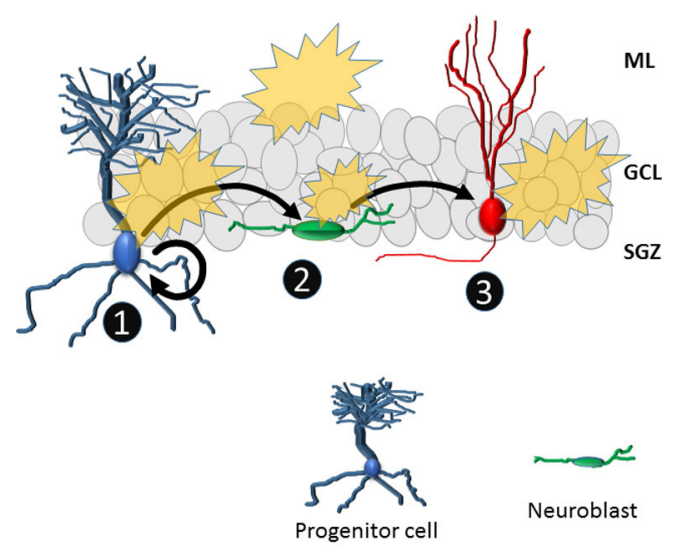

FIGURE 1 | Amyloid plaques affect neurogenesis differently in animal AD models and human AD. (A) No plaques are present in wild-type mice. Progenitor cells divide asymmetrically, leading to the formation of new progenitor cells (1) and neuroblasts (2). Neuroblasts become immature neurons (3) that migrate to their final positions and extend dendrites and axons. (B) Common animal model of AD with hAPP overexpression and plaque formation in the granule cell layer and proliferative area of the dentate gyrus, which may directly affect the cell
C hAPP overexpression only in mature neurons

(Yetman and Jankowsky's animal model)

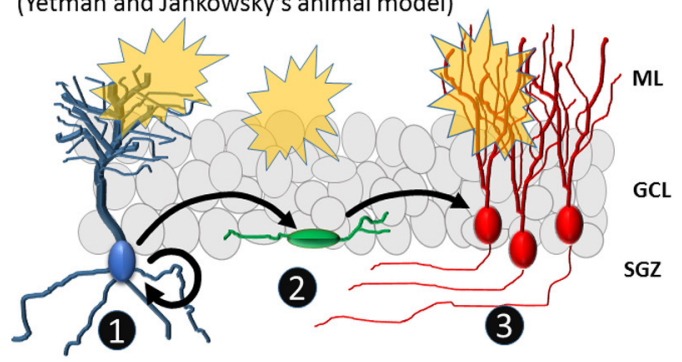

D Human Alzheimer's disease

( According to Jin et al., 2004 and Perry et al., 2012)
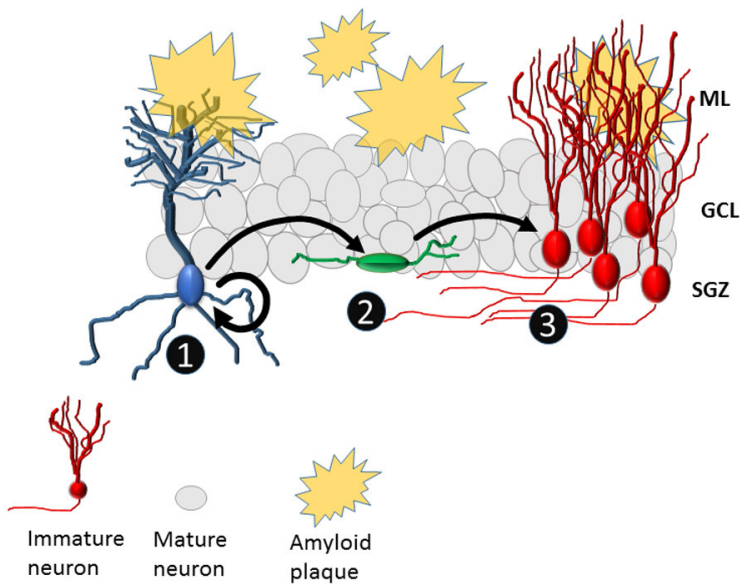

population from which new neurons are born. Normally, the number of immature neurons in transgenic mice is lower than that in wild-type mice. (C) In the animal model created by Yetman and Jankowsky (2013), plaques deposit mainly in the molecular layer of the dentate gyrus, and levels of neurogenesis are similar between transgenic and wild-type mice. (D) In human $A D$, there are plaques in the molecular layer but not around the granule cell layer or proliferative area of the dentate gyrus, and hippocampal neurogenesis is elevated (3). to an increase in neurogenesis-hyperphosphorylated tau (pTau) and mutated PS-1. Therefore, a hypothetical triple transgenic mouse (with hAPP, pTau, and PS-1 mutations) in which only hAPP is excluded from the dentate gyrus could provide clearer insights into how hippocampal neurogenesis is altered during AD. However, there might be several other unknown factors, both internal, related to molecular malfunction, or external, due to environmental effectors. The perfect model, closely resembling the real disease, seems to be challenging, but a closer approach is necessary to avoid the previous conflicts between existing models and the human disease regard neurogenesis.

Although the relevance of hippocampal neurogenesis to cognitive impairments in $\mathrm{AD}$ remains under debate, the assumption that disease-related neurogenesis loss is a key contributor to cognitive impairments could be fundamentally wrong. The evidence shows contradictory information about the aging decrease of neurogenesis and its impact on cognitive performance. Some studies support this view (Drapeau et al., 2003; Wati et al., 2006), but more recent works report no relation between neurogenesis decay with age and memory retention and retrieval (Merrill et al., 2003; Martinez-Canabal et al., 2013a,b). Therefore, there might be no reason for which age-related decreased neurogenesis implicates cognitive impairment. Rather than insufficient neurogenesis, excessive neurogenesis in pathological circumstances could lead to cognitive impairment by altering hippocampal circuits (Lee et al., 2012; Martinez-Canabal et al., 2013b). Therefore, to understand the role of hippocampal neurogenesis in $\mathrm{AD}$-related memory impairment, we need additional transgenic models that exhibit neuropathology more similar to that occurring in humans. In addition, it is critical to understand if $\mathrm{AD}$-associated neurogenesis yields properly connected and functional neurons that can support memory circuits. Immature neurons compared to mature, have different plastic characteristics that could lead to different memory roles. It would be important to understand the memory roles that neurons generated during $\mathrm{AD}$ if any, could develop (Ge et al., 2008). Although Yetman and Jankowsky's mouse model is close to 
the current needs of the field, we urgently need something closer, such as an animal model in which the expression of ADrelated transgenes drives the production of new hippocampal cells.

\section{ACKNOWLEDGMENTS}

The author acknowledged the funding of DGAPA-UNAM post-doctoral fellowships. Also, the kind comments and revision on this manuscript by Dr. Katherine Akers.

\section{REFERENCES}

Baron, R., Nemirovsky, A., Harpaz, I., Cohen, H., Owens, T., and Monsonego, A. (2008). IFNgamma enhances neurogenesis in wild-type mice and in a mouse model of Alzheimer's disease. FASEB J. 22, 2843-2852. doi: 10.1096/fj.08105866

Battista, D., Ferrari, C. C., Gage, F. H., and Pitossi, F. J. (2006). Neurogenic niche modulation by activated microglia: transforming growth factor beta increases neurogenesis in the adult dentate gyrus. Eur. J. Neurosci. 23, 83-93. doi: 10.1111/j.14609568.2005.04539.x

Boekhoorn, K., Joels, M., and Lucassen, P. J. (2006). Increased proliferation reflects glial and vascular-associated changes, but not neurogenesis in the presenile Alzheimer hippocampus. Neurobiol. Dis. 24, 1-14. doi: 10.1016/j.nbd.2006. 04.017

Crews, L., Adame, A., Patrick, C., Delaney, A., Pham, E., Rockenstein, E., et al. (2010). Increased BMP6 levels in the brains of Alzheimer's disease patients and APP transgenic mice are accompanied by impaired neurogenesis. J. Neurosci. 30, 12252-12262. doi: 10.1523/JNEUROSCI.130510.2010

Deng, W., Aimone, J. B., and Gage, F. H. (2010). New neurons and new memories: how does adult hippocampal neurogenesis affect learning and memory? Nat. Rev. Neurosci. 11, 339-350. doi: 10.1038/nrn2822

Drapeau, E., Mayo, W., Aurousseau, C., Le Moal, M., Piazza, P. V., and Abrous, D. N. (2003). Spatial memory performances of aged rats in the water maze predict levels of hippocampal neurogenesis. Proc. Natl. Acad. Sci. U.S.A. 100, 14385-14390. doi: 10.1073/pnas.2334169100
Ermini, F. V., Grathwohl, S., Radde, R., Yamaguchi, M., Staufenbiel, M., Palmer, T. D., et al. (2008). Neurogenesis and alterations of neural stem cells in mouse models of cerebral amyloidosis. Am. J. Pathol. 172, 1520-1528. doi: 10.2353/ajpath.2008.060520

Ge, S., Sailor, K. A., Ming, G. L., and Song, H. (2008). Synaptic integration and plasticity of new neurons in the adult hippocampus. J. Physiol. 586, 3759-3765. doi: 10.1113/jphysiol.2008.155655

Haughey, N. J., Nath, A., Chan, S. L., Borchard, A. C., Rao, M. S., and Mattson, M. P. (2002). Disruption of neurogenesis by amyloid betapeptide, and perturbed neural progenitor cell homeostasis, in models of Alzheimer's disease. J. Neurochem. 83, 1509-1524. doi: 10.1046/j.14714159.2002.01267.x

Jin, K., Galvan, V., Xie, L., Mao, X. O., Gorostiza, O. F., Bredesen, D. E., et al. (2004a). Enhanced neurogenesis in Alzheimer's disease transgenic (PDGFAPPSw,Ind) mice. Proc. Natl. Acad. Sci. U.S.A. 101, 13363-13367. doi: 10.1073/pnas.0403678101

Jin, K., Peel, A. L., Mao, X. O., Xie, L., Cottrell, B. A., Henshall, D. C., et al. (2004b). Increased hippocampal neurogenesis in Alzheimer's disease. Proc. Natl. Acad. Sci. U.S.A. 101, 343-347. doi: 10.1073/pnas.2634794100

Kuhn, H. G., Cooper-Kuhn, C. M., Boekhoorn, K., and Lucassen, P. J. (2007). Changes in neurogenesis in dementia and Alzheimer mouse models: are they functionally relevant? Eur. Arch. Psychiatry Clin. Neurosci. 257, 281-289. doi: 10.1007/s00406007-0732-4

Lee, J. W., Kim, W. R., Sun, W., and Jung, M. W. (2012). Disruption of dentate gyrus blocks effect of visual input on spatial firing of CA1 neurons. J. Neurosci. 32, 12999-13003. doi: 10.1523/JNEUROSCI.2608-12.2012

Lopez-Toledano, M. A., and Shelanski, M. L. (2007). Increased neurogenesis in young transgenic mice overexpressing human $\mathrm{APP}(\mathrm{Sw}, \mathrm{Ind})$. J. Alzheimers Dis. 12, 229-240.

Martinez-Canabal, A., Akers, K. G., Josselyn, S. A., and Frankland, P. W. (2013a). Age-dependent effects of hippocampal neurogenesis suppression on spatial learning. Hippocampus 23, 66-74. doi: 10.1002/hipo.22054

Martinez-Canabal, A., Wheeler, A. L., Sarkis, D., Lerch, J. P., Lu, W. Y., Buckwalter, M. S., et al. (2013b). Chronic over-expression of TGFbetal alters hippocampal structure and causes learning deficits. Hippocampus 23, 1198-1211. doi: 10.1002/hipo.22159
Merrill, D. A., Karim, R., Darraq, M., Chiba, A. A., and Tuszynski, M. H. (2003). Hippocampal cell genesis does not correlate with spatial learning ability in aged rats. J. Comp. Neurol. 459, 201-207. doi: $10.1002 / \mathrm{cne} .10616$

$\mathrm{Mu}$, Y., and Gage, F. H. (2011). Adult hippocampal neurogenesis and its role in Alzheimer's disease. Mol. Neurodegener. 6, 85. doi: 10.1186/1750-13266-85

Perry, E. K., Johnson, M., Ekonomou, A., Perry, R. H., Ballard, C., and Attems, J. (2012). Neurogenic abnormalities in Alzheimer's disease differ between stages of neurogenesis and are partly related to cholinergic pathology. Neurobiol. Dis. 47, 155-162. doi: 10.1016/j.nbd.2012.03.033

Wati, H., Kudo, K., Qiao, C., Kuroki, T., and Kanba, S. (2006). A decreased survival of proliferated cells in the hippocampus is associated with a decline in spatial memory in aged rats. Neurosci. Lett. 399, 171-174. doi: 10.1016/j.neulet.2006.01.056

Yetman, M. J., and Jankowsky, J. L. (2013). Wild-type neural progenitors divide and differentiate normally in an amyloid-rich environment. J. Neurosci. 33, 17335-17341. doi: 10.1523/JNEUROSCI.191713.2013

Yu, Y., He, J., Zhang, Y., Luo, H., Zhu, S., Yang, Y., et al. (2009). Increased hippocampal neurogenesis in the progressive stage of Alzheimer's disease phenotype in an APP/PS1 double transgenic mouse model. Hippocampus 19, 1247-1253. doi: 10.1002/hipo.20587.

Conflict of Interest Statement: The author declares that the research was conducted in the absence of any commercial or financial relationships that could be construed as a potential conflict of interest.

Received: 17 March 2014; accepted: 23 May 2014; published online: 11 June 2014.

Citation: Martinez-Canabal A (2014) Reconsidering hippocampal neurogenesis in Alzheimer's disease. Front. Neurosci. 8:147. doi: 10.3389/fnins.2014.00147

This article was submitted to Neurogenesis, a section of the journal Frontiers in Neuroscience.

Copyright (0) 2014 Martinez-Canabal. This is an openaccess article distributed under the terms of the Creative Commons Attribution License (CC BY). The use, distribution or reproduction in other forums is permitted, provided the original author(s) or licensor are credited and that the original publication in this journal is cited, in accordance with accepted academic practice. No use, distribution or reproduction is permitted which does not comply with these terms. 